ISSN: 2521-5051 (Print)

ISSN: 2521-506X (Online)

CODEN : $A S M C C Q$

\title{
ANALYSIS ON INFLUENCING FACTORS OF INDUSTRIAL POLLUTION TAKING ZHEJIANG PROVINCE AS AN EXAMPLE
}

\author{
Jianya Gu1, Diping Zhang2* \\ ${ }^{1}$ School of Marxism, Zhejiang University of Science and Technology, Hangzhou 310023, China \\ ${ }^{2}$ School of Sciences, Zhejiang University of Science and Technology, Hangzhou 310023, China \\ *Corresponding Author Email: zhangdiping163@163.com
}

This is an open access article distributed under the Creative Commons Attribution License, which permits unrestricted use, distribution, and reproduction in any medium, provided the original work is properly cited.

\section{ARTICLE DETAILS}

\section{Article History:}

Received 12 November 2017 Accepted 12 December 2017

Available online 1 January 2018

\section{ABSTRACT}

In this paper, the principal component analysis (PCA) is used to measure the pollution of industrial pollution in Zhejiang Province. Then, the linear regression of industrial pollution is analyzed. The conclusion is that the emission of industrial waste gas accounts for the largest proportion in industrial pollution. The increase in the per capita GDP, the increase in the proportion of secondary industry GDP and the improvement of urbanization will exacerbate industrial pollution, and industrial governance investment will have the opposite effect. Based on the above, this paper puts forward the relevant countermeasures and suggestions.

\section{KEYWORDS}

Industrial pollution, Influencing factors, Principal component analysis, Multiple linear regression analysis

\section{INTRODUCTION}

In China, the rapid development of industrial economy with industrial pollution prevention and control, has been the focus and key of environmental protection, and effective control of industrial pollution is the focus of Chinese and even global economic sustainable development. For Zhejiang Province, the industrial economy for the city development and environmental protection are of great importance. On the one hand, in recent years, Zhejiang Province industry has a great contribution for GDP growth, of which the proportion of industrial GDP is the largest. On the other hand, with the economic development, technological progress and the acceleration of the industrialization process, accompanied by the industrial "three wastes" caused serious damage to the environment [1].

Therefore, the reduction of industrial pollution emissions is the key to improving the environmental quality of Zhejiang Province. Many studies of industrial pollution abroad show that when environmental protection investment accounts for $1 \%$ to $1.5 \%$ of GDP, the environmental pollution can be controlled basically, so that the environmental conditions will remain at a level acceptable to the people [2]. When environmental protection investment accounts for up to $2 \%-3 \%$, the environment quality can be improved and the basic environmental guarantee and economic as well as social development can be achieved [3]. This paper uses the statistical method to analyze the influencing factors of industrial pollution in Zhejiang Province from 2006 to 2016, and puts forward some suggestions according to the research conclusion.

\section{INFLUENCING FACTORS ANALYSIS OF INDUSTRIAL POLLUTION}

\subsection{Indicator selection}

The choice of indicators is divided into two blocks. The first one is the measure of industrial pollution level, it is from three aspects: (1) industrial emissions, which includes industrial sulfur dioxide emissions and industrial smoke (powder) dust emissions; (2) industrial wastewater, which includes chemical oxygen emissions and ammonia emissions; (3) solid waste of industrial production.
The second one is the influencing factor analysis, choosing four indexes including economic scale, industrial structure, industrial pollution control investment and urbanization level as independent variables, and taking the sequence obtained by principal component analysis as dependent variable to be analyzed by linear regression analysis.

Table 1: Indicator Description

\begin{tabular}{|c|c|c|}
\hline Indicator & Indicator Description & $\begin{array}{l}\text { The } \\
\text { direction of } \\
\text { impact }\end{array}$ \\
\hline Economic size x1 & per capita GDP & Positive \\
\hline $\begin{array}{c}\text { Industrial Structure } \\
\text { x2 }\end{array}$ & $\begin{array}{c}\text { The proportion of GDP in the } \\
\text { secondary }\end{array}$ & Positive \\
\hline $\begin{array}{c}\text { Industrial pollution } \\
\text { control investment x3 }\end{array}$ & $\begin{array}{c}\text { actual use funds of industrial } \\
\text { pollution control }\end{array}$ & negative \\
\hline Urbanization level x4 & $\begin{array}{c}\text { proportion of non - } \\
\text { agricultural population / } \\
\text { total population }\end{array}$ & positive \\
\hline
\end{tabular}

\subsection{Data sources}

The data of this paper mainly come from China Statistical Yearbook and Zhejiang Statistical Yearbook, that is 11 years of data including the emissions data of 2005 - 2015 annual indicators of industrial "three wastes" and the total annual emissions of industrial "three wastes" [4].

\subsection{Analysis of the main components of industrial "three wastes"}

First, industrial waste gas is divided into industrial sulfur dioxide and industrial smoke (powder) dust, industrial wastewater is divided into chemical oxygen emissions and ammonia emissions, industrial solid waste is no longer subdivided, and then the principal component analysis was conducted on the five aspects [5]. The results of principal component analysis princomp process are as follows (Table 2, Table 3, Table 4). 
Table 2: Correlation Coefficient Matrix for Variables

\begin{tabular}{|c|c|c|c|c|c|}
\hline \multicolumn{5}{|c|}{ Correlation Matrix } \\
\hline & $\mathbf{x 1}$ & $\mathbf{x 2}$ & $\mathbf{x 3}$ & $\mathbf{x 4}$ & $\mathbf{x 5}$ \\
\hline $\mathbf{x 1}$ & 1 & 0.9818 & 0.9787 & 0.9765 & 0.9732 \\
\hline $\mathbf{x 2}$ & 0.9818 & 1 & 0.9999 & 0.9989 & 0.9986 \\
\hline $\mathbf{x 3}$ & 0.9787 & 0.9999 & 1 & 0.9992 & 0.9992 \\
\hline $\mathbf{x 4}$ & 0.9765 & 0.9989 & 0.9992 & 1 & 0.9998 \\
\hline $\mathbf{x 5}$ & 0.9732 & 0.9986 & 0.9992 & 0.9998 & 1 \\
\hline
\end{tabular}

Table 3: Eigenvalues of Correlation Coefficient Matrix

\begin{tabular}{|c|c|c|c|c|}
\hline \multicolumn{5}{|c|}{ Eigenvalues of the Correlation Matrix } \\
\hline & Eigenvalue & Difference & Proportion & Cumulative \\
\hline $\mathbf{1}$ & 4.96247 & 4.92622 & 0.9925 & 0.9925 \\
\hline $\mathbf{2}$ & 0.03625 & 0.03498 & 0.0073 & 0.9997 \\
\hline $\mathbf{3}$ & 0.00127 & 0.00126 & 0.0003 & 1 \\
\hline $\mathbf{4}$ & $8.4 \mathrm{E}-06$ & $8.4 \mathrm{E}-06$ & 0 & 1 \\
\hline $\mathbf{5}$ & 0 & 0 & 0 & 1 \\
\hline
\end{tabular}

Table 4: Eigenvectors of Correlation Coefficient Matrix

\begin{tabular}{|c|c|c|c|c|c|}
\hline \multicolumn{5}{|c|}{ Eigenvectors } \\
\hline & Prin1 & Prin2 & Prin3 & Prin4 & Prin5 \\
\hline x1 & 0.44248 & 0.88489 & 0.1157 & 0.08213 & 0.03231 \\
\hline x2 & 0.44874 & -0.1067 & -0.5009 & -0.2993 & -0.6684 \\
\hline x3 & 0.44853 & -0.19 & -0.5351 & 0.11652 & 0.68028 \\
\hline $\mathbf{x 4}$ & 0.44831 & -0.2486 & 0.56994 & -0.6139 & 0.1885 \\
\hline $\mathbf{x 5}$ & 0.44799 & -0.3282 & 0.35288 & 0.71639 & -0.2321 \\
\hline
\end{tabular}

As can be seen from the above table, the first principal component has explained $99.25 \%$ of the total variance, that is, the total amount of information containing the original data reached $99.25 \%$, indicating that it is enough for the first principal component to represent the original five indicators to evaluate the emissions of industrial pollution. From the output Eigenvalue we can see that the contribution rate of the first principal component has reached $99.25 \%$, so only the first principal component can be used to summarize this set of data. And the first principal component is:

$$
\begin{array}{r}
\operatorname{prin} 1=0.442481 \mathrm{x}_{1}+0.448737 \mathrm{x}_{2}+ \\
0.448526 \mathrm{x}_{3}+0.448305 \mathrm{x}_{4}+0.447988 \mathrm{x}_{5}
\end{array}
$$

According to the score of the first principal component, the industrial waste gas, waste water and waste residue are sorted. The results are shown in Table 5. The industrial sulfur dioxide is number 1, industrial smoke (powder) dust is number 2 , and so on.

\section{Table 5: Sort results}

\begin{tabular}{|c|c|c|c|c|c|}
\hline Obs & $\mathbf{1}$ & $\mathbf{2}$ & $\mathbf{3}$ & $\mathbf{4}$ & $\mathbf{5}$ \\
\hline id & 1 & 2 & 3 & 5 & 4 \\
\hline Prin1 & 3.40005 & 0.78032 & -0.2819 & -1.9162 & -1.9822 \\
\hline
\end{tabular}

It can be concluded that the greater the emissions of industrial sulfur dioxide, the greater the degree of industrial pollution, indicating that industrial sulfur dioxide emissions accounted for the largest part of industrial pollution emissions.

According to the first principal component, a new sequence can be obtained (see Table 5).

Table 5: Generating the sequence

\begin{tabular}{|r|r|r|r|r|r|r|r|r|r|r|}
\hline 2005 & 2006 & 2007 & 2008 & 2009 & 2010 & 2011 & 2012 & 2013 & 2014 & 2015 \\
\hline 73.4 & 72.42 & 71.13 & 64.22 & 58.86 & 56.96 & 54.03 & 85.23 & 78.97 & 78.69 & 79.003 \\
\hline
\end{tabular}

\subsection{Linear regression analysis of the industrial "three wastes" influencing factors}

Running Eviews software to get the estimate as follows:

$$
\begin{aligned}
& y=-753.287+21.7311 x_{1}+22.8913 x_{2}-0.9230 x_{3}+8.8911 x_{4} \\
& \mathrm{t}=(-2.92) \quad(2.45) \quad(2.58) \quad(2.27) \quad(-2.35) \\
& R^{2}=0.9289 \quad \overline{R^{2}}=0.7156 \quad S . E=6.1156 \quad F=4.3550 \quad D W=2.5442
\end{aligned}
$$

Given that in the $t$ distribution table, the degree of freedom is $n-2=9$, the critical value, because all, so we can see per capita GDP, the proportion of GDP occupied by the secondary industry, industrial pollution control investment and the scale of urbanization all have a significant impact on the pollution of industrial pollution in Zhejiang Province.

According to the model, we find that the index per capita GDP, the 
proportion of GDP in the secondary industry and the impact of urbanization on industrial pollution are significant, and this effect is positive and can lead to an increase in industrial pollution. For every $1 \%$ increase in GDP, industrial pollution will increase by $21.7311 \%$, and the proportion of GDP in the secondary industry will increase by $22.8913 \%$ for every $1 \%$ of GDP, and 1\% for industrial pollution. Emissions will increase $8.8911 \%$. Industrial pollution control investment for industrial pollution is also significant, but the impact is negative, it can make the negative impact of industrial pollution reduction, that is, industrial pollution control investment for each additional 100 million RMB, industrial pollution emissions will be reduced by $0.9230 \%$.

\section{RECOMMENDATIONS}

Based on the findings of the study, several recommendations are made as follows:

1) To adjust the industrial structure. The proportion of GDP in the secondary industry is greater than that of the tertiary industry and the primary industry, while the secondary industry is mainly industrial and construction, which will lead to the intensification of industrial pollution. Therefore, it is necessary to adjust the industrial structure reasonably and form a technology-intensive industrial pattern.

2) To increase investment in industrial pollution control investment, from the industrial pollution emissions, industrial emissions are of the largest, followed by industrial waste water emissions, so the investment in governance, should be targeted to increase governance investment to get the best results of governance.
3) Industrial waste water must be treated and cleaned prior to discharge and treated separately for wastewater from different industries. Besides it is important to control emissions and make full use of the natural environment of self-purification capacity, and give effective control according to different regions and different periods of emissions.

\section{REFERENCES}

[1] Jianjun, L., Yanjun, L., Changhui, Z., Yankai, Z., Haopeng, S. 2010. The Analysis on the Emission Intensity of the Main Pollutants in Shandong Province from the Year of 2001 to 2007. Environmental Science and Management, 35 (3), 38-40.

[2] Yeung, D. 1992. A differential game of industrial pollution management. Annals of Operations Research, 37 (1), 297-311.

[3] Jianging, Guowei. 2016. Comparison and Countermeasures of industrial pollution control in Beijing, Tianjin and Hebei. Value Engineering, 16 (1), 26-29.

[4] National Bureau of Statistics. 2015. China Statistical Yearbook 20052016. Beijing: China Statistics Press.

[5] Sangodoyin, A.Y. 1995. Characteristics and control of industrial effluent-generated pollution. Environmental Management and Health, 6 (4), 15-18. 